\title{
COMPETENCIA DESLEAL: LA ECONOMÍA DEL ENGAÑO
}

\author{
Ricardo Sanhueza \\ Universidad de Los Andes \\ Benjamín Mordoj \\ Universidad de Chile
}

Resumen: La Ley $\mathrm{N}^{\circ} 20.169$ protege en Chile a competidores y consumidores de la competencia desleal. Es plausible pensar que la Ley exige a los jueces acreditar la aptitud de una conducta potencialmente desleal para desviar clientes desde un competidor a otro, por lo que resulta indispensable evaluar desde la perspectiva económica cuándo una conducta supuestamente desleal es apta para producir el desvío del comercio. Se plantea que cuando se trata de información falsa sobre los atributos de los productos, aplicar la Ley sólo podría tener sentido cuando se trata de bienes de experiencia y de confianza. Asimismo, se plantea que la usurpación de la identidad de un rival constituye un acto de competencia desleal especialmente relevante porque no sólo busca desviar clientela, sino que destruye un mecanismo de mercado para informar verazmente sobre los atributos de los productos. Consideran-

Ricardo Sanhueza. Doctor en Economía, Universidad de Maryland. Profesor de la Universidad de Los Andes (rsanhueza@uandes.cl).

Benjamín Mordoj. Licenciado en Ciencias Jurídicas y Sociales, Universidad de Chile. Profesor Ayudante de Derecho Económico, Universidad de Chile. Abogado asociado de FerradaNehme (bmordoj@fn.cl). 
do que la Ley otorga competencia para conocer este tipo de conflictos a los tribunales ordinarios de justicia, este trabajo puede servir como una guía simple para una interpretación y aplicación de la Ley.

Palabras clave: competencia desleal, información, aptitud de la conducta.

Recibido: agosto 2011; aceptado: septiembre 2011.

\section{THE ECONOMICS OF DECEPTION}

Abstract: Law 20,169 protects competitors and consumers in Chile from unfair competition. As it is plausible to conceive that the Law requires judges to confirm the capability of a potentially unfair conduct geared to divert customers from one competitor to another, it is necessary to asses from an economic perspective when a supposedly unfair conduct is capable to divert trade. This paper argues that when there is false information about the attributes of a product, enforcing the law could only make sense when the products are experience and credence goods. It contends too that usurpation of a rival's identity is an especially relevant form of unfair competition since the intent is not only to divert clientele, but also to destroy a market tool that provides truthful information on the features of products. Since the Law grants jurisdiction to the ordinary courts of justice to resolve this type of disputes, this paper aims to provide a simple guide on interpreting and enforcing the Law.

Keywords: unfair competition, information, conduct potential.

Received: August; accepted: September 2011.

\section{Introducción}

$\mathrm{E}_{\mathrm{n}}$ febrero de 2007 se promulgó la Ley № 20.169 (la Ley) cuyo objeto declarado es proteger a competidores, consumidores y, en general, a cualquier persona afectada en sus intereses por un acto de competencia desleal. La Ley define un acto de competencia desleal como toda conducta contraria a la buena fe o a las buenas costumbres que, por medios ilegítimos, persiga desviar clientela de un agente del 
mercado $^{1}$. La Ley tuvo su origen en una moción parlamentaria para complementar el derecho chileno de la competencia ${ }^{2}$, en parte, porque el Decreto Ley $N^{\circ} 211$ de 1973 (DL 211), que establece el régimen de defensa de la libre competencia, tipifica sólo aquellos actos de competencia desleal realizados con el objeto de alcanzar, mantener o incrementar una posición dominante ${ }^{3}$. Lo anterior difiere del caso de la Ley $\mathrm{N}^{\circ} 20.169$, que busca cautelar de manera simultánea dos bienes jurídicos distintos - el interés del competidor particular y el de los consumidores-, lo que justifica analizar algunas hipótesis que se presentan en los mercados desde la perspectiva de la racionalidad económica de su sanción.

Asimismo, a nuestro juicio, la Ley exige a los jueces acreditar la aptitud de una conducta potencialmente desleal para desviar clientes desde un competidor a otro, tal como se deriva de su propia redacción ${ }^{4}$ y como lo ha señalado una sentencia sobre la materia ${ }^{5}$. Por ello, resulta indispensable evaluar desde la perspectiva económica cuándo una conducta supuestamente desleal es apta para producir el desvío del comercio, lo que - argumentaremos - depende del contexto de información en que las transacciones entre oferentes y consumidores se materializa.

Un tercer aspecto que justifica ahondar en los aspectos económicos de la competencia desleal es que el órgano jurisdiccional a cargo de conocer las demandas al amparo de la Ley es un tribunal no especializado - los tribunales ordinarios en lo civil ${ }^{6}$ - En este contexto, entender la economía que subyace a las conductas sancionadas por la ley se hace indispensable.

Por último, comprender la economía de la competencia desleal permite muchas veces identificar de manera temprana la eficacia de una

\footnotetext{
${ }^{1}$ Artículo 3.

${ }^{2}$ Exposición de Motivos, p. 1.

3 Artículo 3, letra c.

${ }^{4}$ A modo de ejemplo, a propósito de las distintas acciones que el artícu-
} lo 5 de la Ley permite ejercer. El único caso menos claro sería el de la acción de prohibición de un acto no puesto en práctica (letra a). Sin embargo, dado su carácter eminentemente cautelar, el requisito de aptitud se encontraría en la necesidad de acreditar un fumus bonis iuris.

${ }^{5}$ Décimo Juzgado Civil de Santiago, Sentencia Rol C-23384-2008, de 27 de mayo de 2009, Considerando Vigésimo: "[L]a actora no puede pretender que la población de este país se confunda, ya sea por la morfología, colores y demás elementos utilizados por quienes elaboran este tipo de productos".

${ }^{6}$ Artículo 8. 
conducta para desviar comercio entre competidores. Esto permitiría a un juez, y a potenciales demandantes, anticipar la tipicidad efectiva de una conducta, lo que podría precaver los litigios frívolos. Esto es especialmente relevante en Chile porque no existen reglas claras ni eficaces para atribuir los costos de un litigio infundado a un demandante ${ }^{7}, y$ donde, a diferencia de lo que ocurre en otros países, un juez no puede desestimar una acción en las etapas preliminares de un procedimiento ${ }^{8}$.

Por todo lo anterior, este trabajo pretende abordar algunos casos en que la inconsistencia entre bienes jurídicos protegidos puede presentarse (descuentos o precios mentirosos y publicidad engañosa), así como un ejemplo en que efectivamente ambos bienes jurídicos sí pueden resultar coherentes y, al mismo tiempo, la conducta resulta apta para desviar clientela a favor del sujeto activo (usurpación de identidad). Lo anterior, con el objeto de contribuir a una mejor interpretación de la Ley $\mathrm{N}^{\circ} 20.169$, otorgando una simple guía para ser considerada por el juez en un hipotético caso.

La Ley considera un acto de competencia desleal la difusión de hechos o aseveraciones, incorrectos o falsos, que induzcan a error respecto a las características o la calidad y, en general, sobre las ventajas proporcionadas por los bienes y servicios ofrecidos, sean propios o ajenos $^{9}$. Asimismo, serían actos de competencia desleal las aseveraciones incorrectas o falsas en relación al precio ${ }^{10}$, y el aprovechamiento indebido de la reputación ajena por medio de inducir a confundir los propios bienes, servicios, actividades y signos distintivos con los de un tercero $^{11}$.

Las ofertas de precios rebajados son comunes en muchos mercados. A veces suelen promocionarse como descuentos porcentuales respecto al precio normal durante un cierto periodo. Otras veces se trata de ofertas de precios rebajados pero condicionadas a que el vendedor

${ }^{7}$ Véase, por ejemplo, Mery (2006).

8 Es lo que se conoce en el derecho anglosajón como summary judgment. En Chile no existe una institución similar y se observa escaso interés por incorporarla a nuestro régimen legal. De hecho, el proyecto de reforma a la justicia procesal civil que consagra un nuevo Código Procesal, se limita a introducir un control de admisibilidad solamente formal de las demandas (Boletín N 6567-07 Cámara de Diputados, artículo 236).

${ }^{9}$ Artículo 4, letra b.

${ }^{10}$ Artículo 4, letra b.

${ }^{11}$ Artículo 4, letra a. 
cuente con disponibilidad de inventario o capacidad para concretarlas. En ninguno de estos casos el consumidor puede comprobar la veracidad de la oferta y existe espacio para el engaño — rebajas porcentuales que no son tales o bien ofertas de precios que no están disponibles_- En este contexto, cabe preguntarse en qué medida la ley que regula la competencia desleal puede proteger los intereses de los consumidores (uno de sus objetivos declarados) y evitar que ofertas de precios engañosas sean utilizadas para desviar clientela entre competidores.

La racionalidad económica que subyace la regulación de la competencia desleal es que las transacciones entre compradores y vendedores se dan normalmente en condiciones de información incompleta, por lo que es factible mentir respecto a los atributos de los productos con el objeto de desviar clientela hacia el propio negocio. Sin embargo, ello no siempre es así. La idoneidad o aptitud del engaño para desviar clientela depende del papel que juega la falta de información en la transacción ${ }^{12}$. Por ello, evaluar en un caso particular si una conducta constituye un acto de competencia desleal requiere entender en qué medida la difusión de información falsa es un medio idóneo para desviar clientela.

Por otra parte, las empresas saben que los consumidores tienen información limitada respecto a los atributos de los productos que ofrecen, y que existe la posibilidad de que un competidor oportunista tome ventaja. Por ello, existen mecanismos de mercado operando cuyo objetivo es informar de manera creíble a los consumidores respecto a los atributos de los bienes que ofrecen. Además, es plausible pensar que si un competidor intenta desviar clientela hacia su negocio engañando respecto a los atributos de sus productos, sus rivales tengan incentivos para desenmascarar el engaño. Sin embargo, como veremos, ambos mecanismos podrían ser insuficientes, por lo que regular la competencia desleal sería en algunas ocasiones necesario, dependiendo del tipo de bien comercializado.

${ }^{12}$ El Código Civil de 1857, que es la principal fuente de regulación para nuestros actos y contratos, supone normalmente condiciones de simetría de información entre las partes en una transacción, salvo casos excepcionales. Como ejemplo de estas excepciones se encuentran: (i) la nulidad por error de hecho sobre la sustancia o calidad esencial de la cosa (artículo 1454); (ii) la acción de saneamiento por vicios redhibitorios u ocultos de la cosa adquirida por el comprador no experto (artículo 1861); y, (iii) la acción rescisoria por lesión enorme, cuando el precio de transacción de un inmueble se alejó considerablemente de su justo precio (artículos 1888 y siguientes). 
En cambio, la usurpación de identidad de un competidor, aprovechando su reputación mediante la copia de sus signos distintivos (práctica conocida como trade dress), constituye un acto de competencia desleal porque, por medio del engaño, desvía clientela hacia el propio negocio. Sin embargo, como veremos, esta conducta tiene consecuencias más allá del desvío de comercio - destruye un mecanismo de mercado por medio del cual las empresas informan a los consumidores de los atributos ocultos de los bienes y servicios que ofrecen-.

El trabajo está organizado de la siguiente manera. En la próxima sección analizamos en qué medida la ley que regula la competencia desleal protege los intereses de los consumidores cuando se trata de precios con descuentos engañosos. La tercera sección trata el problema de la publicidad falsa respecto a los atributos de los productos. Se analiza en qué medida la información falsa respecto a los atributos de los bienes resulta idónea para desviar clientela hacia el propio negocio, y si los mecanismos de mercado y la competencia resultan suficientes para evitar actos de competencia desleal. La cuarta sección trata la usurpación de identidad entre competidores y cómo ella destruye mecanismos de mercado para informar a los consumidores. La última sección concluye con algunas reflexiones sobre la aplicación de la Ley en sus distintos ámbitos.

\section{Precios con descuentos engañosos}

Una de las variables más importantes en la decisión de compra es el precio, por ello, una empresa podría intentar desviar clientela desde los rivales promocionando descuentos que en realidad no son tales. Un descuento engañoso puede tomar dos formas. La primera es promocionar descuentos porcentuales que no son reales. La segunda es ofrecer descuentos que en realidad no están disponibles cuando el cliente los solicita. En esta sección analizamos en qué medida sancionar estas prácticas beneficia a los consumidores, que es uno de los bienes jurídicos que la Ley señala proteger.

\subsection{Descuentos porcentuales mentirosos}

Es común observar que una tienda promocione descuentos de sus precios en un porcentaje determinado. Sin embargo, al no especificarse la base sobre la cual se aplicó el descuento, ello puede no ser verdad. 
Para ejemplificar, suponga que una tienda ofrece un descuento del $25 \%$ en el precio los días martes. Sin embargo, este descuento es respecto al precio que tiene los días lunes que en realidad es $20 \%$ superior al precio que cobra los demás días de la semana. Así, la rebaja no fue en realidad del $25 \%$ sino de tan sólo un $10 \%$ si se consideran las condiciones normales de precio durante el resto de la semana.

Si bien, desde la perspectiva de la ley que regula la competencia desleal, este tipo de rebajas engañosas podría ser objeto de sanción, es concebible imaginar situaciones en que hacerlo podría resultar contrario a los intereses de los consumidores (Rubin, 1991). Ello podría ocurrir si la tienda que promociona un descuento del $25 \%$, a pesar de que en realidad es sólo del $10 \%$, atrae consumidores más sensibles al precio que comprarían en la tienda y dejarían de hacerlo en otras. Las demás tiendas, sin embargo, como una estrategia defensiva se verían forzadas a reaccionar reduciendo sus propios precios aun por debajo del precio rebajado en $10 \%$. Asimismo, la reacción de los rivales podría llevar a la primera tienda a reducir el precio por sobre el 10\% inicial, y el descuento mentiroso desencadenar una dinámica competitiva que intensificaría la competencia en precios. El resultado sería que los consumidores terminan accediendo a menores precios y comprando más.

Por otra parte, no es claro que una estrategia de descuentos engañosos como ésta resulte en un desvío de comercio hacia la tienda que desencadenó la competencia más intensa. Todo depende de cómo reaccionen los rivales. La evidencia casual sugiere que el resultado suele ser una guerra de precios en la que todos los competidores reducen fuertemente sus precios para defender sus participaciones de mercado. Las múltiples guerras de precios entre supermercados donde las participaciones de mercado no se han alterado sustantivamente son un ejemplo de que no siempre se produce un desvío de clientela.

Si la persecución de casos de descuentos engañosos resultara en que los comercios fueran mucho más cautos a la hora de ofrecer descuentos, ello podría eventualmente hacer menos probable que se desencadenen dinámicas competitivas que hicieran más intensa la competencia en precio, lo que obviamente resultaría en que los consumidores pagaran precios más altos. De este modo, una aplicación irrestricta de este tipo legal debe analizar su aptitud y consistencia con otros bienes jurídicos distintos de la protección de un competidor porque podría tener efectos sobre los consumidores. 
Respecto a este último punto, sin embargo, conviene hacer un par de consideraciones adicionales. La primera es que, aun cuando la competencia pudiera resultar más intensa en un contexto en que las empresas engañan en sus descuentos en el precio, los consumidores pudieran ver disminuido su bienestar si se erosiona su confianza en los proveedores y requieren incurrir en mayores costos de búsqueda para suministrarse de manera confiable un bien o un servicio ${ }^{13}$. En este sentido, los descuentos mentirosos importarían un costo para los consumidores. La segunda consideración es que las reducciones de precio engañosas encarecen establecer relaciones de confianza entre oferentes y consumidores, y la confianza es un elemento esencial para que las empresas logren la lealtad de sus consumidores que les permita acceder a una participación de mercado sustentable en el tiempo ${ }^{14}$.

\subsection{Descuentos no disponibles}

Suele ser común ver publicidad con ofertas de precios rebajados sujetos a disponibilidad, en particular cuando se trata de la venta de servicios como, por ejemplo, viajes aéreos, paquetes vacacionales, o estadías en hoteles. Pero también ocurre en comercios que venden bienes complementarios como, por ejemplo, un supermercado donde la publicidad de precios rebajados de algunos productos ganchos sirven para atraer clientes y vender otros bienes ${ }^{15}$.

La imposibilidad de los consumidores para comprobar si existía o no disponibilidad al momento de comprar hace posible que este tipo de ofertas pueda ser un mecanismo para desviar clientela desde los rivales promocionando productos con descuentos que en realidad no están disponibles. Sin embargo, como argumenta Rubin (1991), al igual que

${ }^{13}$ Los descuentos mentirosos son la expresión de oportunismo en un contexto de información incompleta, lo que incrementa los costos de transacción. Para mayor detalle véase, por ejemplo, Williamson (1985, cap. 2).

${ }^{14}$ Ver para el caso del comercio electrónico, por ejemplo, Urban et al. (2000) y Reichheld y Schefter (2000).

${ }^{15} \mathrm{La}$ venta a pérdida de un producto gancho para incentivar la compra de otros bienes es una práctica denominada loss leading. Recientemente, la Fiscalía Nacional Económica validó su licitud en la mirada del derecho de la competencia. Véase Resolución de archivo Denuncia de Cámara de Comercio de San Vicente Tagua-Tagua, por presuntos precios predatorios en el rubro panificador. 
en el caso de los descuentos engañosos, prohibir este tipo de descuentos podría resultar en que los consumidores terminen pagando mayores precios.

Consideremos, por ejemplo, el caso de las promociones de rebajas no disponibles que se dan en industrias como las líneas aéreas, los hoteles o el arriendo de automóviles. Una característica común a estas industrias es que los oferentes enfrentan costos fijos importantes y su costo medio depende de manera crucial de la tasa de utilización de sus inversiones. Por otra parte, los servicios que ofrecen no son almacenables en el sentido que si no se venden en un determinado periodo la posibilidad de hacer esa venta ya no está disponible en el periodo próximo. Por ejemplo, si un hotel no vende una habitación un día determinado no es factible venderla en el futuro. Ambas características llevan a que los proveedores deban gestionar sus ingresos (hacer revenue management) cambiando constantemente el precio a medida que va cambiando la tasa de utilización de su capacidad para minimizar el costo medio de proveer el servicio. Como consecuencia, en condiciones como éstas, los precios rebajados que se publicitan sólo estarían disponibles de manera irregular. Cuando la capacidad ociosa es elevada, y no se prevé llenarla a los precios de lista, la oferta de precios rebajados estaría disponible. Pero si, por el contrario, la demanda es tal que el oferente del servicio prevé que su capacidad se llenará a los precios de lista, los precios rebajados dejarían de estar disponibles.

$\mathrm{Si}$, en este tipo de industrias, se prohibiera o sancionara fuertemente la promoción de descuentos que eventualmente no estarán disponibles, o bien se obligara al oferente a especificar la disponibilidad a esos precios, todo el proceso de gestión de ingresos se vería entrampado. Los oferentes de viajes, hoteles, arriendo de automóviles o vuelos, podrían verse desincentivados de hacer ofertas a precios reducidos porque existe la posibilidad de que su capacidad instalada se agote y no puedan cumplir. El resultado es que la tasa de utilización promedio de la capacidad instalada sería menor, y los costos medios se incrementarían y ello llevaría a un aumento de precios. Aplicar la ley que regula la competencia desleal en este contexto no protege a los consumidores, por lo que su interpretación debe ser coherente con esta realidad, considerando que ello es también un bien jurídico protegido por la Ley cuya sanción conllevaría una lesión al bienestar de los consumidores y la dinámica competitiva. 
La situación es distinta en el caso de las ofertas de precio sin respaldo de inventario en industrias en que no existen indivisibilidades y los productos se pueden almacenar. En estos casos, la utilización de ofertas de precio sin respaldo de inventarios sólo busca desviar comercio desde los rivales y no existirían consideraciones de eficiencia económica que las justifiquen, por lo que su sanción no conllevaría una lesión al bienestar de los consumidores o a la dinámica competitiva.

\section{Publicidad engañosa respecto a los atributos}

En un mercado de productos homogéneos, el precio es la variable más importante en la decisión de compra. Sin embargo, el mundo se caracteriza por una oferta diferenciada de bienes y servicios. Esta diferenciación puede venir dada por los distintos atributos que tiene el producto o bien por su imagen de marca. En este último caso, poco importa si los productos son físicamente idénticos, son distintos si los consumidores consideran que no son sustitutos suficientemente buenos.

La diferenciación entre productos puede ser horizontal o vertical. Cuando están horizontalmente diferenciados, a un mismo precio, distintos consumidores preferirán distintos productos. Es el caso, por ejemplo, de las bebidas gaseosas. Como las preferencias de los consumidores son heterogéneas, a un mismo precio algunos preferirán gaseosas de sabor naranja mientras que otros de sabor a lima. Cuando la diferenciación es vertical, en cambio, a un mismo precio todos los consumidores prefieren un solo producto. Éste es el caso de la diferenciación basada en la calidad. Por ejemplo, si a los consumidores se les ofreciera a un mismo precio un automóvil con un sistema de frenos convencionales y otro idéntico pero con un sistema de frenos ABS, todos elegirían este último. En este caso ambos bienes están verticalmente diferenciados.

A diferencia de lo que en ocasiones podría ocurrir con los descuentos engañosos, en el caso de la publicidad engañosa respecto a los atributos del producto, el engaño importa un costo en términos de eficiencia económica. Jordan y Rubin (1979) plantean que si un consumidor es inducido por la información falsa a comprar, su bienestar se vería mermado porque de no haber existido engaño hubiese comprado otro bien. Asimismo, los rivales perderían ventas producto del engaño que de otra manera hubiesen podido materializar. Así, la publicidad engañosa respecto a los atributos de los bienes implicaría una asignación 
ineficiente de los recursos. Los consumidores terminarían realizando compras que no hubiesen efectuado a vendedores que no hubiesen escogido de no haber mediado el engaño.

\subsection{Información, atributos de los bienes y posibilidad de engaño}

El engaño respecto a los atributos de los bienes y servicios sólo tiene sentido si las transacciones se dan en un contexto de información incompleta. Por eso, antes de analizar en qué medida la difusión de información falsa respecto a los atributos de los bienes resulta un medio apto para desviar clientela, es indispensable entender cuál es el papel que juega la información en las transacciones.

El trabajo seminal de Nelson (1970) permite explorar la importancia que tiene la información en distintos tipos de transacciones. El autor argumenta que existen dos clases de bienes: los bienes con atributos de búsqueda y los bienes con atributos de experiencia. Los bienes con atributos de búsqueda son aquellos cuyas características (incluida la calidad) pueden ser conocidas por el comprador antes de realizar la compra. En estos casos basta la inspección directa del bien para conocer sus características relevantes. Un ejemplo de un bien de búsqueda es una camisa. Por medio de la inspección directa del producto el consumidor puede conocer la calidad de la confección, el diseño, la calidad de la tela, etc.

En estos casos, los incentivos a entregar información falsa respecto a los atributos del producto para desviar clientela son tenues. Los consumidores pueden conocer los atributos de los bienes por inspección directa antes de comprar, y el engaño no es un medio eficaz para desviar clientela. Si un vendedor mintiera sobre los atributos del producto, el engaño quedaría expuesto fácilmente. En este caso, la publicidad y la información que provee el vendedor pretenden informar de los atributos del producto, dónde adquirirlo, su precio, etc., pero de manera veraz (Nelson, 1974) ${ }^{16}$.

${ }^{16}$ Nelson (1974) reconoce la posibilidad de que cuando ir de compra resulta costoso, un oferente de un bien de búsqueda podría exagerar algunos atributos para atraer al cliente. Éste, a pesar de descubrir, antes de comprar el bien, que el oferente exageró sus atributos valorados, no sigue buscando otro proveedor para no incurrir nuevamente en el costo de búsqueda. Sin embargo, argumenta que existen costos de reputación para un oferente que hace esto, lo cual hace menos relevante en este caso el incentivo a engañar. 
Los bienes con atributos de experiencia, en cambio, son aquellos cuyas características relevantes, como, por ejemplo, la calidad, la resistencia, durabilidad, etc., sólo son posibles de determinar por el cliente una vez que los ha adquirido, consumido o utilizado. Es el caso, por ejemplo, de los electrodomésticos. Las distintas marcas en oferta suelen ser aparentemente similares pero difieren en su calidad y durabilidad. Algunas marcas tendrán el desempeño esperado para este tipo de productos, otras, en cambio, requerirán de mantenimiento continuo y durarán menos que la vida útil promedio. Como en este caso la inspección directa no provee información respecto a los atributos relevantes, el consumidor sólo logra conocer la calidad y la durabilidad del producto una vez que lo ha adquirido y lo ha usado por un tiempo.

A diferencia de lo que ocurría con los bienes de búsqueda, cuando se trata de bienes con atributos de experiencia podrían existir incentivos a engañar respecto a los atributos relevantes como, por ejemplo, la calidad. La producción de bienes de mejor calidad implica mejores materias primas, mejor ingeniería y un sistema de control de calidad más exigente, por lo que es más cara que la producción de baja calidad. Así, un oferente oportunista podría manipular rentablemente la información que entrega a los consumidores respecto a la calidad del producto. En concreto, le convendría difundir falsamente que está ofreciendo productos de alta calidad, cobrar un precio mayor, pero en definitiva proveer un producto de baja calidad. En este caso, el engaño resultaría eficaz para desviar clientela porque el consumidor es incapaz de reconocer los atributos relevantes sin haber previamente adquirido y utilizado el producto.

El problema de los atributos ocultos y la posibilidad de engaño es aún más agudo en otro tipo de bienes identificados por Darby y Karni (1973), los que tienen atributos de confianza ${ }^{17}$. En este caso, a un consumidor no experto le resulta imposible juzgar los atributos del bien o el servicio aun después de haberlo adquirido y consumido. Un ejemplo es la compra de verduras regadas con agua de pozo. La verdad es que resulta imposible saber, aun después de consumirlas, si ello es o no verdadero. Obviamente, en estos casos la posibilidad de engaño es aun mayor que en el caso de los bienes de experiencia, y la divulgación de información falsa respecto a los atributos podría ser un medio eficaz para desviar clientela.

${ }^{17}$ Estos bienes o servicios se denominan en inglés credence goods. 
La taxonomía entre bienes de búsqueda, experiencia y confianza resulta analíticamente útil para entender la idoneidad del engaño para desviar clientela. Sin embargo, en la práctica, las características de los bienes y servicios suelen no ser asimilables exclusivamente a una de estas categorías. Ellos pueden mostrar en distinto grado y de manera simultánea atributos de búsqueda, experiencia y confianza. No obstante, se puede colegir que en la medida que los bienes y servicios tengan en mayor medida atributos de experiencia y confianza, la idoneidad del engaño para desviar clientela en el mercado es mayor, por lo que su sanción al amparo de la Ley puede resultar justificada.

\subsection{Publicidad engañosa y relevancia de la Ley}

Las transacciones entre compradores y vendedores se dan en un contexto de información incompleta, por lo que es posible que el engaño sea idóneo para desviar clientela. Sin embargo, como veremos, existen mecanismos de mercado operando que permiten a las empresas informar de manera veraz y creíble sobre los atributos de sus productos. Asimismo, las transacciones se materializan normalmente en ambientes competitivos, por lo que resulta interesante analizar si la competencia resulta en la exposición del engaño.

\section{Mecanismos de mercado para informar sobre los atributos}

Como vimos más arriba, el engaño respecto a los atributos de los bienes ofrecidos es relevante cuando se trata de bienes de experiencia o de confianza. Por eso, las empresas están dispuestas a invertir para informar creíblemente sobre las características que los consumidores no observan - o no se encuentran en condiciones de observar a bajo costo- antes de comprar. Existen varios mecanismos de mercado para ello.

Uno es ofrecer garantías que puedan exigirse si los atributos del producto no son los ofrecidos ${ }^{18}$. Sin embargo, las garantías podrían ser

${ }^{18}$ Esta solución ya se encuentra, en algún sentido, incorporada en nuestro ordenamiento jurídico, a través del derecho legal de garantía consagrado en el artículo 21 de la Ley $\mathrm{N}^{\circ} 19.496$, sobre Protección de los Derechos de los Consumidores, aunque de un modo limitado (tres meses desde la recepción del bien). Respecto a los aspectos económicos de las garantías como señal de calidad véanse, por ejemplo, Spence (1977) y Gal-Or (1989). 
muy poco efectivas cuando el precio del producto es muy bajo y existen costos de exigirlas ${ }^{19}$; o bien cuando es difícil definir cuál debería ser el desempeño adecuado del bien o el servicio prestado ${ }^{20}$; o cuando la durabilidad del bien no sólo depende del fabricante sino que también del uso que el consumidor le haya dado al producto. Por eso, las garantías no siempre pueden resolver el problema de informar creíblemente a los consumidores de los atributos ocultos de los bienes. Además, la garantía es en sí misma un bien de experiencia porque su valor sólo es develado una vez que un consumidor la exige y en este sentido también puede resultar en un mecanismo ineficaz para asegurar calidad ${ }^{21}$.

Nelson (1974) ha sugerido, sin embargo, que, en el caso de los bienes de experiencia, la publicidad podría ser por sí misma informativa sobre la calidad del producto, independiente de la veracidad del mensaje. Quienes producen bienes de alta calidad estarían dispuestos a gastar más en publicidad que quienes anuncian alta calidad pero en realidad ofrecen baja calidad. La razón es que la publicidad induce una primera venta, pero ella es mucho más valiosa para quien suministra la calidad ofrecida. Quien ofreció la calidad prometida obtiene ventas repetidas de su producto, pero el que maliciosamente engañó a los consumidores no, porque se correría la voz de que se trata de un mal producto y la sanción por los consumidores resulta posible ${ }^{22}$. Por eso, cuando se trata de productos con ventas que se repiten en el tiempo, se argumenta que el gasto publicitario sería un mecanismo que informa creíblemente respecto a los atributos ocultos del bien o el servicio.

Klein y Leffler (1981), por otra parte, han sugerido que la inversión que realiza una empresa en construir una marca reconocida y valiosa, y mantenerla, podría ser otro mecanismo que en sí mismo resulte informativo respecto a la calidad oculta de bienes y servicios. Para construir una marca y mantenerla, una empresa debe realizar gastos en publicidad, promoción y merchandising que son específicos a la empre-

${ }^{19}$ Un ejemplo es la garantía que ofrecía un fabricante de alimentos para bebés (colados). Si el consumidor no estaba satisfecho con el producto debía enviar la etiqueta del envase a una casilla postal en Costa Rica. Obviamente que el costo del trámite era mayor que el costo de desechar el alimento si estaba en mal estado sin más.

${ }^{20}$ Probablemente muchos pacientes de cirugías estéticas esperan más de las intervenciones de lo que obtienen.

${ }^{21}$ Agradecemos esta observación a uno de los árbitros.

22 La idea de Nelson (1974) ha sido desarrollada formalmente por Kilstrom y Riordan (1984). 
sa y sus productos. Una vez realizadas estas inversiones, la empresa las recupera sólo si logra realizar ventas repetidas en el tiempo, lo que obviamente requiere que la empresa suministre la calidad ofrecida de ese producto. Así, la inversión en el desarrollo de una marca, al igual que el gasto en publicidad, resultaría ser informativa respecto a la veracidad de la promesa de calidad y otros atributos que la empresa realiza.

En la misma línea, Shapiro (1983) plantea que los consumidores infieren la calidad considerando la calidad de los productos ofrecidos por la empresa en el pasado, y que la construcción de una reputación de calidad permitiría informar verazmente a los consumidores sobre la calidad y otros atributos de los productos ofrecidos. La empresa que pretende desarrollar una reputación de calidad podría hacerlo por medio de establecer un precio introductorio menor que el costo de producir el bien en baja calidad. Las pérdidas que asume durante este periodo introductorio constituyen una inversión para establecer su reputación, que sólo recuperaría si logra repetir ventas en el tiempo cobrando un premio por la calidad que provee. El que los productos con reputación de calidad se puedan vender con un premio sobre los costos induce a los oferentes a mantenerla en el tiempo.

La literatura sobre los mecanismos de mercado que permiten informar verazmente a los consumidores respecto a los atributos ocultos de los bienes ha sido un esfuerzo sistemático por caracterizar las condiciones de oferta y demanda en que ellos operan. Por eso, el que existan estos mecanismos no implica que sea innecesaria una ley que regule la competencia desleal porque bajo determinadas condiciones ellos no resultan eficaces. Sin embargo, cuando uno observa que algunos de estos mecanismos son utilizados por una empresa, lo lógico es inferir que en ese caso concreto sí resultan eficaces, si no las empresas no invertirían en ellos.

\section{Competencia y exposición del engaño}

Cuando una empresa informa de manera falsa respecto a los atributos de un producto lo que busca es desviar ventas desde los rivales hacia sí misma. Por eso cabe preguntarse si el mismo proceso competitivo no resultaría suficiente para exponer el engaño sin necesidad de una ley especial que regule la competencia desleal. Los oferentes cuyos productos tienen mejores atributos deberían tener incentivos a informar verazmente a los consumidores y exponer un eventual engaño 
de sus competidores. Por ello, no sería necesario regular. La competencia generaría información veraz respecto a los atributos de los productos. Pitofsky (1977), sin embargo, argumenta que estos incentivos no siempre existirían.

Por ejemplo, en mercados oligopólicos muy concentrados, los oferentes podrían evitar revelar información respecto a los atributos de los bienes para evitar una guerra competitiva en el ámbito del diseño de los productos que sea mutuamente desventajosa. Las guerras competitivas en diseño de productos normalmente implican mayores costos, los que no siempre se pueden traspasar a precio. Pitofsky (1977) argumenta que ello ha ocurrido en la industria alimenticia donde se ha desatado una guerra por ofrecer productos bajos en calorías, lo que a la larga ha encarecido los productos y deteriorado los márgenes. En Chile ocurre algo similar en el mercado de las tarjetas de crédito. Los emisores lanzan tarjetas con cada vez más beneficios para los tarjeta-habientes como, por ejemplo, créditos sin intereses hasta por un año, descuentos sustantivos en la compra de combustible, o bien descuentos para viajar. En casos como estos existen escasos incentivos para promover las características del producto propio y exponer las debilidades de los competidores.

Por otra parte, en mercados que son altamente concentrados y es caro entrar, informar de manera muy precisa respecto a los atributos de los productos puede abrir oportunidades de entrada a nuevos rivales. Por ejemplo, el mercado de las galletas fue tradicionalmente servido por pocos oferentes que comercializaban con marcas reconocidas, sin que se produjera entrada. Sin embargo, ello cambió con la creciente preocupación de un segmento de clientes por el contenido calórico del producto, la cantidad de grasas saturadas y otros atributos nutricionales. Cuando esta información comenzó a publicarse en los envases, y los clientes fueron más conscientes de su importancia, se abrió la posibilidad de entrada para productores más pequeños. Su ingreso al mercado obedeció a que fueron capaces de diseñar productos con atributos nutricionales valorados por un segmento del mercado que resultó más fácil de identificar cuando los oferentes establecidos fueron obligados a revelar información sobre las características nutricionales de sus productos.

En una industria más atomizada, donde existe un mayor número de competidores, cada uno con una baja participación de mercado, tampoco existirían incentivos a exponer el engaño. Los beneficios que obtendría cada competidor de exponer el engaño serían muy pequeños 
porque tienen una baja participación de mercado, y, además, la exposición del engaño de un competidor constituye un bien público para todos los demás (Jordan y Rubin, 1979). En este contexto, la competencia no promovería, sino que más bien inhibiría, la exposición del engaño.

Pitofsky (1977) argumenta, además, que exponer el engaño de los rivales tiene sus propios inconvenientes. El primero es que puede no ser una estrategia competitiva rentable. Los presupuestos de marketing de una empresa son limitados y exponer el engaño de un rival implica asumir el costo de oportunidad de dejar de resaltar las bondades del propio producto. Si el efecto en la participación de mercado de promover los propios productos es mayor que el denunciar rivales, la puja competitiva no incentiva exponer el engaño.

Pitofsky (1977) también identifica otras razones de orden práctico que inhibirían la exposición del engaño. Una es que puede ser difícil probar que un rival está entregando información falsa respecto a los atributos de sus productos, y existe el riesgo de judicializar la competencia $^{23}$, con los costos públicos y privados ya señalados ${ }^{24}$. Otra es que

${ }^{23}$ De hecho, una de las conductas que la propia Ley sanciona en su artículo 4, letra g, - $\mathrm{y}$ que la jurisprudencia antimonopolios también reconoce como conducta potencialmente desleal - es el ejercicio manifiestamente abusivo de acciones judiciales efectuado con la finalidad de entorpecer la operación de un agente del mercado (práctica conocida como sham litigation en el derecho comparado).

${ }^{24}$ Un caso de judicialización como el que hemos descrito se encuentra en el dictamen $N^{\circ} 1235$, de 6 de enero de 2003, emitido por la antigua Comisión Preventiva Central. En dicho caso, el denunciante alegó que la campaña publicitaria del alimento para gatos marca Whiskas constituía un acto de competencia desleal, al señalar que 8 de cada 10 gatos prefieren Whiskas. El denunciante alegó, entre otras cosas, que: "[L]a afirmación que se hace por medio de esta propaganda no tiene asidero, de acuerdo a las cifras obtenidas de un análisis del mercado chileno de alimentos para gatos, donde los alimentos Whiskas aparecen con una venta en todos los segmentos investigados que en ningún caso alcanza el $80 \%$, que sería lo lógico en su concepto, si tal preferencia fuera verdadera $[. .$.$] de suerte entonces que resulta falsa la pretensión de la denun-$ ciada de que de cada 10 gatos 8 prefieran el alimento Whiskas (§3)". La Comisión Preventiva Central, al rechazar la denuncia, indicó que: “[N]o se puede inferir de la conducta de la denunciada que con su aviso promocional pretende eliminar o restringir la competencia, puesto que este hecho no es idóneo para lo primero ni impone un barrera que provoque lo segundo. En cuanto a que la entorpezca, tal ocurriría si de ello se derivara en una limitante para la concurrencia a los mercados, virtud o efecto del que carece un aviso publicitario, tanto más cuando afirmaciones como las de este tipo son comunes en el mercado publicitario y usadas generalmente, también por la denunciante (§17)”. 
los medios podrían ser reacios a una publicidad confrontacional considerando que le venden espacio publicitario a más de un competidor.

En suma, la rivalidad no siempre soluciona el problema de la difusión de información falsa respecto a los atributos de los bienes vendidos, por lo que existe espacio para la regulación de la competencia desleal.

\section{Usurpación de identidad}

Los envases, la publicidad y otros signos distintivos permiten a un oferente transmitir su identidad e imagen de marca a los consumidores. La imagen de la marca permite comunicar ideas y atributos de manera que ellos sean asociados a los productos (Gardner y Levy, 1999). La marca de un producto también permite informar sobre los beneficios funcionales y emocionales que se pueden derivar de su consumo (Aaker, 1996; y Aaker y Joanchimsthaler, 2000), y posicionarlo en la mente de los consumidores respecto a los productos ofrecidos por los competidores (Aaker, 1991 y 1996; East, 1997; y Rook 1999). Es así que, en el caso de los bienes de búsqueda, las marcas y sus signos distintivos serían un medio por el cual un productor provee información al consumidor que incrementa el valor de los bienes consumidos y le reduce los costos de búsqueda.

La usurpación de identidad, por medio de inducir a los consumidores a confundir los propios bienes, servicios, actividades y signos distintivos con los de un tercero, tiene como fin apropiarse de la reputación ajena para desviar clientela, por lo que no cabe duda de que se trata de un acto de competencia desleal.

Cuando la usurpación de identidad no es penalizada, los signos distintivos dejan de ser informativos y se debilitan los incentivos a invertir en desarrollar una marca. A las empresas les resultaría más difícil asociar características funcionales y emocionales a sus productos y posicionarlos en la mente de los consumidores. Ello entramparía el mecanismo por el cual los oferentes agregan valor a los productos y servicios que comercializan. Por otra parte, los costos de búsqueda de los consumidores aumentarían porque ya no podrán confiar en los signos distintivos en su elección de compra, y tendrían que desarrollar actividades de búsqueda y testeo para poder identificar los oferentes que proveen los atributos que ellos valoran. 
La relevancia de prevenir la usurpación de identidad por medio de una ley que regule la competencia desleal, sin embargo, va más allá de evitar que por medio del engaño se desvíe clientela hacia el propio negocio, sino que resulta indispensable para preservar las inversiones en marcas como mecanismos para informar creíblemente a los consumidores de los atributos de los bienes (Klein y Leffler, 1981 y Shapiro, 1983).

Si la usurpación de identidad no es penalizada y la marca con sus signos distintivos dejan de ser informativos, el mecanismo de mercado para separar oferentes de alta calidad de los de baja calidad dejaría de ser efectivo. Como se sabe desde el trabajo seminal de Akerlof (1970), cuando los consumidores no pueden distinguir a oferentes de alta y baja calidad se produce una reducción de la calidad promedio de los bienes ofrecidos en el mercado, pudiendo llegarse al extremo que los oferentes de alta calidad salgan del mercado. Esto importaría un costo en bienestar cuando existen consumidores dispuestos a pagar por bienes y servicios de alta calidad pero ellos no pueden ser provistos porque el mecanismo para informar creíblemente respecto al atributo se ha vuelto ineficaz.

\section{Conclusión}

La ley que regula la competencia desleal pretende, al menos formalmente, proteger a competidores y consumidores de las conductas contrarias a la buena fe o las buenas costumbres que, por medios ilegítimos, persiguen desviar clientela. Sin embargo, su aplicación en el caso de ofertas de descuentos de precio engañosas puede desincentivar una rivalidad más intensa entre competidores, o bien entrabar el proceso de gestión de ingresos, lo que podría afectar el bienestar de los consumidores — que es otro bien jurídico protegido por la Ley y por el DL 211-. En ambos casos, los consumidores podrían terminar pagando precios más altos. Por ello, su aplicación debería considerar los eventuales efectos sobre la intensidad de la competencia en precio y si existen o no razones de eficiencia que justifiquen que en ciertas circunstancias las ofertas no puedan ser satisfechas.

Por otra parte, en los casos de información falsa sobre los atributos de los productos, es indispensable evaluar en qué medida el engaño es un instrumento apto para desviar clientela. La aplicación de la ley de 
competencia desleal cobra sentido cuando se trata de bienes de experiencia y de confianza, es decir, cuando los atributos no son observables antes de comprar y consumir el producto. Además, en cada caso, se debe evaluar en qué medida las empresas utilizan mecanismos de mercado eficaces para revelar creíblemente sus atributos a los consumidores, porque ello podría constituir indicio de que la información provista es veraz.

El ámbito en que resulta imprescindible aplicar la Ley es en los casos de usurpación de identidad (trade dress). En estos casos es obvio que el objetivo es apropiarse de la reputación ajena para desviar clientela, lo que genera ineficiencias en la asignación de recursos. Pero, además, la sanción se hace imprescindible porque la conducta destruye las marcas, un mecanismo de mercado por medio del cual las empresas buscan informar verazmente a sus consumidores respecto a los atributos de sus productos, cuestión que puede afectar el bienestar de los consumidores y entrampar el proceso competitivo.

La aplicación de la Ley por los tribunales ordinarios de justicia debiera tener en cuenta estos elementos, en especial porque en Chile no existe una etapa formal de admisibilidad que permita desestimar tempranamente las demandas manifiestamente frívolas o inútiles, lo que ahorraría costos públicos y privados. Entre otras cosas, hemos enfatizado la importancia de que los tribunales evalúen la aptitud o idoneidad de la conducta para desviar el comercio, lo que supone entender la economía de la competencia desleal.

\section{BibliografíA}

Aaker, D. Managing Brand Equity: Capitalizing on the Value of a Brand Name. New York: The Free Press y Simon \& Schuster, 1991.

Building Strong Brands. New York: The Free Press/Simon \& Schuster, primera edición, 1996.

Aaker, D. y E. Joanchimsthaler. Brand Leadership. New York: The Free Press/ Simon \& Schuster, primera edición, 2000.

Akerlof, G. "The Market for Lemons". The Quarterly Journal of Economics 84 (3), 1970: 488-500.

Bork, R. The Antitrust Paradox. New York: The Free Press, 1978.

Darby, M. y E. Karni. "Free Competition and the Optimal Amount of Fraud". Journal of Law and Economics 16 (1), 1973: 67-88.

East, R. Consumer Behavior: Advances and Applications in Marketing. Hemel Hemstead Hertfordshire: Prentice Hall Europe, primera edición, 1997. 
Gal-Or, E. "Warranties as a Signal of Quality". Canadian Journal of Economics 22 (1), 1989: 50-61.

Gardner, B. y S. Levy. "The Product and the Brand”. En D. Rook (ed), Brand, Consumers, Symbols \& Research: Sidney J. Levy on Marketing. Thousand Oaks, California: Sage Publications, 1999: 131-40.

Jordan, E. y P. Rubin. "An Economic Analysis of the Law of False Advertising”. The Journal of Legal Studies 8 (3), 1979: 527-553.

Kilstrom, R. y M. Riordan. "Advertising as a Signal". Journal of Political Economy 92 (3), 1984: 427-450.

Klein, B. y K. Leffler. "The Role of Market Forces in Assuring Contractual Performance". Journal of Political Economy 89 (4), 1981: 615-641.

Mery, R. "Una Aproximación Teórica y Empírica a la Litigación Civil en Chile". Latin American and Caribbean Law and Economics Association, 2006

Nelson, P. "Information and Consumer Behavior". Journal of Political Economy 78, 1970: 311-329.

"Advertising as Information". Journal of Political Economy 82, 1974: 729-754.

Pitofsky, R. "Beyong Nader: Consumer Protection and the Regulation of Advertising". Harvard Law Review 90 (4), 1977.

Reichheld, F. y P. Schefter. "E-Loyalty: Your Secret Weapon on the Web". Harvard Business Review 78 (July/August), 2000:105-113.

Rook, D. "Products and Brands". En D. Rook (ed.), Brand, Consumers, Symbols \& Research: Sidney J. Levy on Marketing. Thousand Oaks, California: Sage Publications, 1999: 127-129.

Rubin, P. "The Economics of Regulating Deception". Cato Journal 10 (3), 1991: 667-690.

Shapiro, C. "Premium for High Quality Products as Returns to Reputation". The Quarterly Journal of Economics 98 (4), 1983: 659-680.

Spence, M. "Consumer Misperception, Product Failure and Producer Liability". Review of Economic Studies 44 (138), 1977: 561-573.

Urban, G., F. Sultan y W. Qualls. "Placing Trust at the Center of Your Internet Strategy". Sloan Management Review 42 (Fall), 2000: 39-49.

Williamson, O. The Economic Institutions of Capitalism. New York: The Free Press, 1985. 